\section{International Overdose Awareness Day - August 31, 2017}

International Overdose Awareness Day is a global event held each year on August 31. This event aims to raise awareness that overdose deaths are preventable, reduce stigma about substance use disorders and drug-related deaths, highlight community drug-related services, and support evidence-based policies and programs to prevent or reduce drug-related harms. Additional information is available at https://www.overdoseday.com.

The opioid overdose epidemic resulted in the deaths of approximately 300,000 persons in the United States during 1999-2015, including 33,000 in 2015 (1). The first wave of deaths began in 1999 and included deaths involving prescription opioids (1). It was followed by a second wave, beginning in 2010, and characterized by deaths involving heroin (2). A third wave started in 2013, with deaths involving synthetic opioids, particularly illicitly manufactured fentanyl (IMF) (3). IMF is now being used in combination with heroin, counterfeit pills, and cocaine (3).

Reports in this issue of $M M W R$ 1) highlight how increases in deaths and death rates related to heroin and synthetic opioids mirror data tracking illicit drugs and 2) describe the role of IMF and fentanyl analogs in 281 overdose deaths in 2 months in Ohio. Additional data and information on CDC's state-level efforts to address drug-related deaths are available at https://www.cdc.gov/ drugoverdose/index.html.

\section{References}

1. CDC. CDC Wonder. Atlanta, GA: US Department of Health and Human Services, CDC; 2016. https://wonder.cdc.gov/

2. Rudd RA, Paulozzi LJ, Bauer MJ, et al. Increases in heroin overdose deaths_-28 states, 2010 to 2012. MMWR Morb Mortal Wkly Rep 2014;63:849-54.

3. Drug Enforcement Administration. DEA intelligence brief. Counterfeit prescription pills containing fentanyls: a global threat. Washington, DC: US Department of Justice, Drug Enforcement Administration; 2016. https://www.dea.gov/docs/Counterfeit $\% 20$ Prescription\%20Pills.pdf

\section{Trends in Deaths Involving Heroin and Synthetic Opioids Excluding Methadone, and Law Enforcement Drug Product Reports, by Census Region - United States, 2006-2015}

Julie K. O’Donnell, $\mathrm{PhD}^{1}$; R. Matthew Gladden, $\mathrm{PhD}^{1}$; Puja Seth, $\mathrm{PhD}^{1}$

Opioid overdose deaths quadrupled from 8,050 in 1999 to 33,091 in 2015 and accounted for $63 \%$ of drug overdose deaths in the United States in 2015. During 2010-2015, heroin overdose deaths quadrupled from 3,036 to 12,989 (1). Sharp increases in the supply of heroin and illicitly manufactured fentanyl (IMF) are likely contributing to increased deaths (2-6). CDC examined trends in unintentional and undetermined deaths involving heroin or synthetic opioids excluding methadone (i.e., synthetic opioids)* by the four U.S. Census regions during 2006-2015. Drug exhibits (i.e., drug products) obtained by law enforcement and reported

* Death data are from CDC WONDER (https://wonder.cdc.gov/). "Synthetic opioids excluding methadone" is a defined cause of death category.

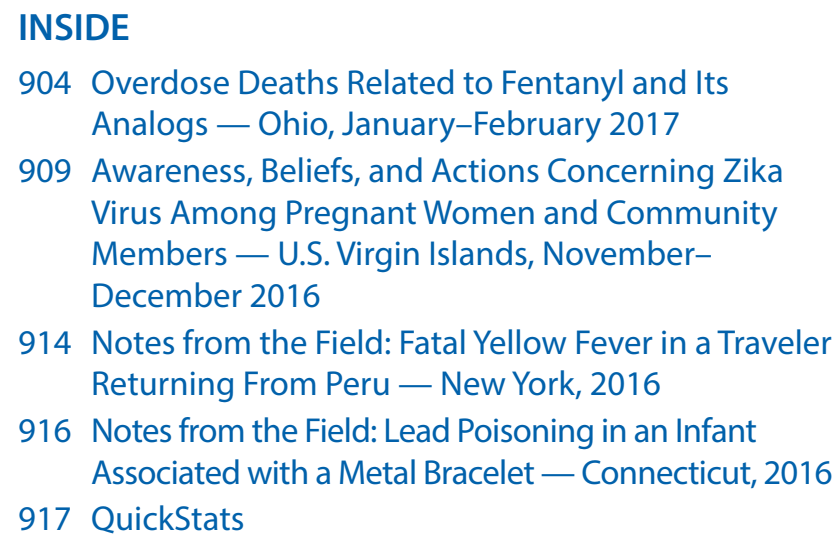

916 Notes from the Field: Lead Poisoning in an Infant Associated with a Metal Bracelet — Connecticut, 2016

917 QuickStats

Continuing Education examination available at https://www.cdc.gov/mmwr/cme/conted_info.html\#weekly.

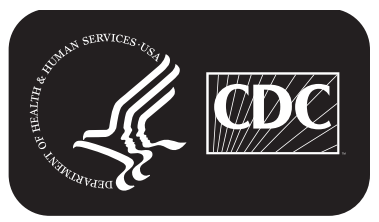

